\title{
High incidence of retinopathy in neuropathy proven diabetic patients: A cohort study
}

\section{Vijayashree Shrirang Gokhale, Neha Chaggan Chaudhari, Arjun Lal Kakrani, Bhushan Pradyut Shah}

Department of Medicine, Dr. D.Y. Patil Medical College and Research Centre, Pimpri, Pune, Maharashtra, India

Address for the Correspondence: Dr. Vijayashree Shrirang Gokhale, 9B, Nandadeepshri Cooperative Housing Society, Sector 26, PCNTDA, Nigdi, Pune - 411 044, Maharashtra, India. E-mail: vijayashreegokhale@ gmail.com

\begin{tabular}{|l|}
\hline Access this article online \\
\hline Website: www.ijmedph.org \\
\hline DOI: $10.4103 / 2230-8598.165952$ \\
\hline Quick response code:
\end{tabular}

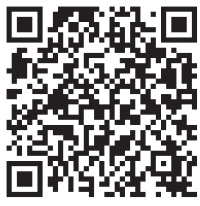

Background: Diabetes and diabetic complications are becoming major "health problems" in India. Diabetes affects all tissues, causing neuropathy, vasculopathy, myopathy, etc. Retina is both vascular and sensory neural tissue, and perhaps the damage is also two-fold. Aims and Objectives: To study incidence of diabetic retinopathy (DR) in a cohort of diabetic patients with nerve conduction velocity (NCV) proven neuropathy. Materials and Methods: a total of 50 diabetic patients aged more than 30 years, with NCV - proven diabetic neuropathy were selected for the study from a Tertiary Care Hospital in semi-rural Maharashtra. Fundoscopy after midriasis and fluorescein angiography, where indicated were performed in all patients. Data were tabulated and analyzed by multivariate analysis and then subjected to regression analysis and anova. Results: Of cohort of 50, 38 patients had retinopathy $(76 \%)$, mean age of patients with retinopathy was 55.3, a male preponderance was seen $72.7 \%$. Conclusions: higher incidence of retinopathy was seen in diabetic patients with neuropathy more so in patients with sensory neuropathy. Thus making us reflect on the possibility: of DR also being a neuropathy, to begin with and whether neuroprotective agents will have a role in preventing and postponing DR.

Key words: Fluorescein angiography, nerve conduction velocity, retinopathy

\section{INTRODUCTION}

India is soon destined to become "The Diabetes Capital" of the world. ${ }^{[1]}$ With diabetes come its dreaded complications, and target organ damage. ${ }^{[2]}$ In the past decade, some success has been achieved in the management of diabetic eye disease and diabetic kidney disease. ${ }^{[3]}$ However, all efforts have to be made to prevent and postpone these complications.

Neuropathy is a common complication in Indian diabetes, both large fiber and small fiber types. Prevalence varying between $29 \%$ and $33 \%$ in various Indian studies. ${ }^{[4,5]}$ Retina is mostly neural tissue, with neural cells in all 10 layers, ${ }^{[6]}$ all prone to the same damage as other neural tissue by end glycation products. Blood vessels in retina are of small caliber and similar to those in the glomerulus of kidney. There is an established relationship in incidence of retinopathy and nephropathy, mostly that both are microangiopathies, however, the tissue and the environment is different.

Diabetic neuropathy includes diabetic peripheral neuropathy and diabetic autonomic neuropathy. The "glycation end products" are very toxic to nerves and can have a direct effect on neural tissue. As duration of diabetes increases, the vasa nervosum (tiny blood vessels supplying nutrition to nerves) get affected, and contribute to the nerve damage.

In late stages it will be difficult to assess whether neural damage came first or vascular damage. In

This is an open access article distributed under the terms of the Creative Commons AttributionNonCommercial-ShareAlike 3.0 License, which allows others to remix, tweak, and build upon the work non-commercially, as long as the author is credited and the new creations are licensed under the identical terms.

For reprints contact: reprints@medknow.com

How to cite this article: Gokhale VS, Chaudhari NC, Kakrani AL, Shah BP. High incidence of retinopathy in neuropathy proven diabetic patients: A cohort study. Int J Med Public Health 2015;5:289-92. 
this study, an attempt was made to find incidence of retinopathy in a cohort of diabetic patients who already had proof of nerve damage.

\section{Aims and objectives}

To study the incidence of diabetic retinopathy (DR) in a cohort of diabetic patients with nerve conduction velocity (NCV) proven peripheral neuropathy.

\section{MATERIALS AND METHODS}

This was a cohort study done at a Tertiary Care Hospital in semirural Maharashtra. Diabetic patients aged more than 30 years were subjected to NCV test using clarity octopus NCV/electromyography machine, and NCV was reported by neurophysician.

\section{Exclusion criteria}

The presence of other co-existing diseases, which may also produce neuropathy, retinopathy like:

1. Alcoholic neuropathy (all alcoholic patients were excluded)

2. HIV-positive patients were excluded (by history)

3. Patients with thyroid dysfunction (both hyper and hypothyroid, by history and thyroid function tests)

4. Patients with peripheral vascular disease (by examination and Doppler studies where indicated)

5. Hypertension (by history, blood pressure recording, and presence of left ventricular hypertrophy on electrocardiography)

Fundoscopy after midriasis was performed by an ophthalmologist in all these patients. Fluorescein angiography was performed where indicated. Optical coherence tomography: Though not performed in our study, is a new and reliable technique to detect early changes in the retina). Data were tabulated. Descriptive statistics of quantitative parameters recorded. Retinopathy score was derived by conversion.

Retinopathy score is given as [Table 1].

Since the available retinopathy data were in the form of classes such as mild-nonproliferative DR (NPDR), moderate NPDR, severeNPDR, proliferative DR (PDR) and PDR with clinically significant macular edema (CSME) etc., it was converted to retinopathy score (quantitative format-as a prerequisite for analysis). Depend on severity of the retinopathy, mild-NPDR was scored as 1 , moderateNPDR as 2, severe-NPDR as 3, PDR as 4 and with CSME as 5. The correlation coefficient was obtained separately for each of the five subgroups of DR. Variables showing significant correlation with retinopathy were further tested for regression. Data were initially analyzed for correlation between retinopathy score and other variables [Tables 2 and 3]. Variables showing correlation with retinopathy were further tested for regression and ANOVA [Tables 4 and 5]. Clearance and consent for all of the above was obtained from Institutional Ethics Committee.

\section{Diabetic peripheral neuropathy}

Neuropathy diagnosed by NCV test. Sensory nerve conduction study is performed by electrical stimulation of a peripheral nerve and recording from a purely sensory portion of the nerve, such as on a finger. Like the motor studies, sensory latencies are on the scale of milliseconds. Sensory amplitudes are much smaller than the motor amplitudes, usually in the microvolt $(\mu V)$ range. The sensory $\mathrm{NCV}$ is calculated based on the latency and the distance between the stimulating and recording electrodes.

\section{Diabetic retinopathy}

\section{Nonproliferative diabetic retinopathy}

The presence of hemorrhages, microaneurysms, hard exudates, soft exudates, venous bleeding and intra retinal microvascular abnormality.

\section{Proliferative diabetic retinopathy}

The presence of new vessels on disc and neo vascularization elsewhere.

\section{Clinically significant macular edema}

Thickening of the retina located $\leq 500 \mu \mathrm{m}$ from the center of the macula.

\section{RESULTS}

Study group cohort $n=50$

All the participants of this cohort had NCV proven diabetic peripheral neuropathy, with subdivision as shown in Figure 1.

Table 1: Retinopathy score
\begin{tabular}{lcccc}
\hline Mild-NPDR & Moderate NPDR & Severe NPDR & PDR & CSME \\
\hline 1 & 2 & 3 & 4 & 5 \\
\hline $\begin{array}{l}\text { NPDR = Nonproliferative diabetic retinopathy, PDR = Proliferative diabetic } \\
\text { retinopathy, CSME = Clinically significant }\end{array}$
\end{tabular}

\begin{tabular}{lcccc} 
Table 2: Age and retinopathy correlation & \\
\hline \multirow{2}{*}{ Parameter } & \multicolumn{2}{l}{ Retinopathy (mean \pm SD) } & Z & $\boldsymbol{P}$ \\
\cline { 2 - 3 } & Yes $(\boldsymbol{n}=\mathbf{3 3})$ & No $(\boldsymbol{n}=\mathbf{1 7})$ & & \\
\hline Age (years) & $55.3 \pm 10.3$ & $58.9 \pm 11.3$ & 1.12 & $>0.05$ \\
\hline
\end{tabular}

$\mathrm{SD}=$ Standard deviation

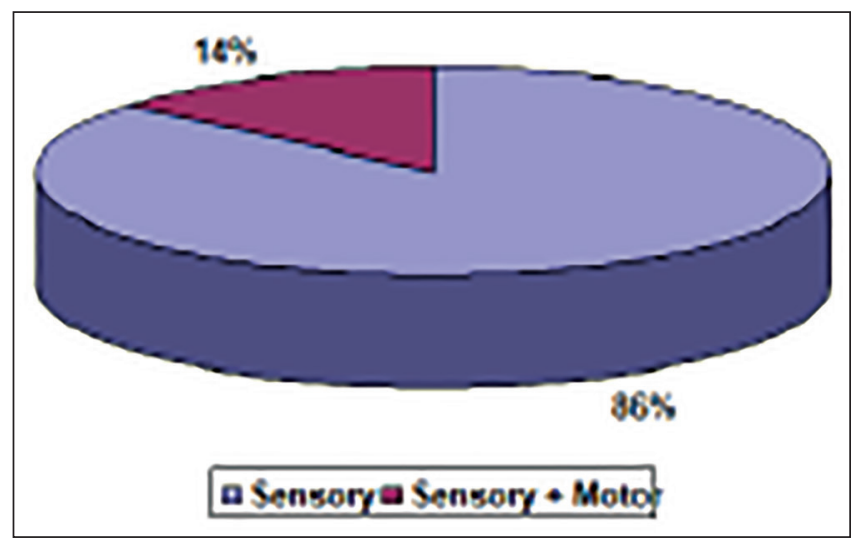

Figure 1: NCV-wise neuropathy distribution of cases in study group 


\begin{tabular}{|c|c|c|c|c|c|c|c|c|}
\hline Variables & Age & Duration & HbA1c & Triglycerides & Sensory neuro & Motor neuro & Retinopathy score & Micral \\
\hline Age & 1.00 & 0.23 & -0.20 & -0.16 & -0.06 & -0.34 & -0.14 & 0.04 \\
\hline Duration & & 1.00 & $0.34^{*}$ & -0.12 & 0.16 & -0.03 & $0.35^{*}$ & $0.49^{* *}$ \\
\hline $\mathrm{HbA} 1 \mathrm{c}$ & & & 1.00 & 0.20 & 0.25 & 0.11 & $0.46^{\star *}$ & $0.43^{* *}$ \\
\hline Triglycerides & & & & 1.00 & 0.21 & 0.06 & 0.20 & 0.16 \\
\hline Sensory neuro & & & & & 1.00 & -0.11 & $0.29^{*}$ & $0.30^{*}$ \\
\hline Motor neuro & & & & & & 1.00 & 0.02 & -0.01 \\
\hline Retinopathy score & & & & & & & 1.00 & $0.46^{* *}$ \\
\hline Micral & & & & & & & & 1.00 \\
\hline
\end{tabular}

${ }^{*}$ Correlation is significant at the 0.05 level (two-tailed), $* *$ Correlation is significant at the 0.01 level (two-tailed)

\begin{tabular}{|c|c|c|c|c|}
\hline Model & $R$ & $R^{2}$ & Adjusted $R^{2}$ & SE of the estimate \\
\hline 1 & 0.294 & 0.086 & 0.067 & 1.4370 \\
\hline
\end{tabular}

\section{Table 5: Anova analysis}

\begin{tabular}{llccccc}
\hline \multicolumn{7}{c}{ ANOVA } \\
\hline & $\begin{array}{l}\text { Sources of } \\
\text { variance }\end{array}$ & $\begin{array}{c}\text { Sum of } \\
\text { squares }\end{array}$ & $\boldsymbol{d f}$ & $\begin{array}{c}\text { Mean } \\
\text { square }\end{array}$ & $\boldsymbol{F}$ & Significant \\
\hline 1 & Regression & 9.381 & 1 & 9.381 & 4.543 & 0.038 \\
& Residual & 99.119 & 48 & 2.065 & & \\
& Total & 108.500 & 49 & & & \\
\hline
\end{tabular}

Independent variable- sensory neuropathy score, dependent variable-retinopathy score, Model $=$ Linear regression

Retinopathy was detected in 38 patients sub-classified in Figure 2.

Age-wise distribution of patients, was similar in retinopathy plus group (mean age 55.3 years) and those without retinopathy (mean age 58.3 years) however on sex-wise distribution, a male preponderance was seen, that is, $33(72.7 \%)$ males and $9(27.3 \%)$ females.

Retinopathy score was derived and regression analysis carried out.

Correlation

\section{Regression analysis \\ DISCUSSION}

In our cohort study, of diabetic patients with NCV proved neuropathy, retinopathy was detected in 38 of the 50 patients $(76 \%)$, which is very high incidence. In a study at Sankara Netralaya Chennai, prevalence of DR was $18 \%$ in urban diabetic population. ${ }^{[7]}$ In the CURES study, prevalence of DR in urban Chennai diabetic population was $17.6 \% \cdot{ }^{[8]}$ Arvind comprehensive eye study reported a prevalence of DR in rural south India to be $10.5 \%$, a study by Raman Kutty in 1999, in urban Kerala reported DR prevalence of 18.75\%, Tariq Qureshi, Nausheen Abdullah, Shagufta, in 2013 concluded that DR is highly prevalent in Kashmir. ${ }^{[0]}$

Prevalence of DR in the USA by various studies is at an average $50.3 \%$, in the United Kingdom 39\%, Austrailia 29.3\%. A study conducted by Mohan showed that the prevalence of DR and

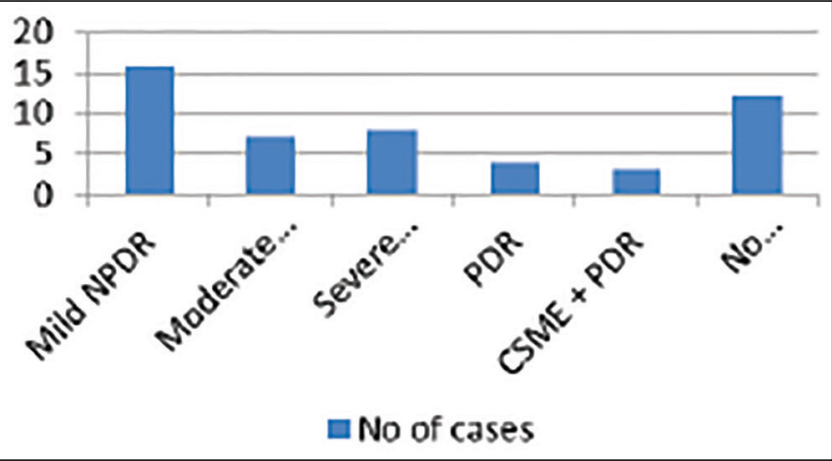

Figure 2: Retinopathy wise distribution in study group $(n=50)$

nephropathy is less as compared to many other ethnic groups. Rema showed in CURES $^{[8]}$ study in South Indian people that the DR prevalence was $17.6 \%$, significantly lower than age-matched western counterparts.

In a study to detect prevalence of neuropathy, Ashok et al., compared incidence of retinopathy in patients with and without neuropathy and found a higher incidence in those with neuropathy. ${ }^{[5]}$

Duration of diabetes correlated directly with the presence of retinopathy in our study.

This is similar to most of the studies mentioned above. Rema et al. in CURES study, reported that for every 5 years increase in duration, risk of DR increased by $1.89 \% .^{[8,10,11]}$

Studies which investigated the nerve cell damage in retina.

In 1998, Mizutani et al. ${ }^{[12]}$ studied Muller cell changes in human DR they hypothesized that Muller glial cells, the principal glial cells of retina produce factors capable of modulating blood flow, vascular permeability and cell survival and that their processes surround all blood vessels in the retina and that these neural cells may be responsible for angiopathy.

Brownlee, ${ }^{[13,14]}$ in his article "the pathophysiology of diabetic complications" has put forth multiple mechanisms for diabetic complications. First he states that certain cells in the body (the endothelial cell, mesangial cell, and shwaan cell of nervous tissue), become target cells because they cannot restrict entry of glucose, and diabetic hyperglycemia increases this intracellular glucose load. 
What follows is a cascade of events, and multiple mechanisms come into play: Increased flux through polyol pathway, increased production of advanced glycation end products precursors, protein kinase $\mathrm{C}$ activation, free fatty acid induced increased production of reactive oxygen species. Some unifying mechanisms finally do the damage.

Further in our study, we found a higher incidence of retinopathy in patients with sensory neuropathy.

\section{CONCLUSIONS}

In this cohort of NCV proven diabetic neuropathy patients, Incidence of DR was $76 \%$, most common type of retinopathy found in our patients was NPDR followed by PDR and the least common was PDR + CSME.

In our study, the mean age of patients with retinopathy was 55.3 years.

The incidence of retinopathy was more in male patients $(72.72 \%)$.

Duration of diabetes, HbA1C, and microalbuminuria showed a direct correlation.

All patients had undergone NCV test. Sensory neuropathy was the most common type of neuropathy followed by sensory + motor mixed neuropathy. Pure motor affection was not seen in any patient. Sensory neuropathy showed correlation with retinopathy score as shown in regression analysis. It is further confirmed by regression analysis and $t$-test. Although the magnitude of regression is low, it is statistically significant. Motor neuropathy did not show significant correlation with retinopathy score, hence not tested for regression.

This may suggest a direct toxic effect of diabetes on neural tissues of the body and those too sensory neural tissues, namely peripheral lower limb sensory nerves and "sensory retina". However our study group was small, so further large group studies will be required to prove this point.

\section{Clinical implications}

Since retina is neural tissue first, DR may be an early form of neuropathy, with vascular changes coming as a consequence. Neuroprotective agents (methylcobalamine, glutathione, and cerebrolysin) may help postpone and to some extent prevent DR, hence they should be used early in the disease.

\section{Acknowledgments}

The authors wish to acknowledge the contribution to the study by Department of Neurology, Dr. D. Y . Patil Medical College, Pimpri Pune, NCV studies were conducted and reported by them. And also wish to acknowledge the contribution by Dr. R. P. Gupta HOD Department of Ophthalmology, Dr. D. Y. Patil Medical College Pimpri Pune. Fundoscopy, Flourescine Angiography was conducted and reported by them.

\section{Financial support and sponsorship}

Dr. D. Y. Patil Medical College and Research Centre, Pimpri, Pune.

\section{Conflicts of interest}

There are no conflicts of interest.

\section{REFERENCES}

1. Mohan V, Pradeepa R. Epidemeology of diabetes in different regions of India. Health Adm 2009;22:1-18.

2. King P, Peacock I, Donnelly R. The UK Prospective Diabetes Study (UKPDS): clinical and therapeutic implications for type 2 diabetes. $\mathrm{Br} \mathrm{J}$ Clin Pharmacol 1999;48:643-48.

3. Tight blood pressure control and risk of macrovascular and microvascular complications in type 2 diabetes: UKPDS 38. UK Prospective Diabetes Study Group. BMJ 1998;317:703-13.

4. Anjana RM, Ali MK, Pradeepa R, Deepa M, Datta M, Unnikrishnan R, et al. The need for obtaining accurate nationwide estimates of diabetes prevalence in India - Rationale for a national study on diabetes. Indian J Med Res 2011;133:369-80.

5. Ashok S, Ramu M, Deepa R, Mohan V. Prevalence of neuropathy in type 2 diabetic patients attending a diabetes centre in South India. J Assoc Physicians India 2002;50:546-50.

6. Rosenblatt MJ, Benson WE. Diabetic retinopathy. In: M. Yanoff, J. Duker. Ophthalmology. 3rd ed., Ch. 6.19. 2008.

7. Raman R, Rani PK, Reddi Rachepalle S, Gnanamoorthy P, Uthra S, Kumaramanickavel G, et al. Prevalence of diabetic retinopathy in India: Sankara Nethralaya diabetic retinopathy epidemiology and molecular genetics study report 2. Ophthalmology 2009;116:311-8.

8. Rema M, Premkumar S, Anitha B, Deepa R, Pradeepa R, Mohan V. Prevalence of diabetic retinopathy in urban India: The Chennai Urban Rural Epidemiology Study (CURES) eye study, I. Invest Ophthalmol Vis Sci 2005;46:2328-33.

9. Qureshi T, Abdullah N, Shagufta. Prevalence of diabetic retinopathy in Kashmir, India - A hospital based study. Glob J Med Public Health 2013;2:1-6.

10. Rema M, Ponnaiya M, Mohan V. Prevalence of retinopathy in non insulin dependent diabetes mellitus at a diabetes centre in southern India. Diabetes Res Clin Pract 1996;34:29-36.

11. Rema M, Pradeepa R. Diabetic retinopathy: An Indian perspective. Indian J Med Res 2007;125:297-310.

12. Mizutani M, Gerhardinger C, Lorenzi M. Müller cell changes in human diabetic retinopathy. Diabetes 1998;47:445-9.

13. Brownlee M. Biochemistry and molecular cell biology of diabetic complications. Nature 2001;414:813-20.

14. Brownlee M. The pathobiology of diabetic complications: A unifying mechanism. Diabetes 2005;54:1615-25. 